\title{
Primary Pigmented Nodular Adrenocortical Disease and Cushing's Syndrome
}

\section{atualização}

\section{ANelia HoRvath Constantine Stratakis}

Section on Endocrinology \&

Genetics, Developmental

Endocrinology Branch, National

Institute of Child Health and

Human Development, National Institutes of Health, Bethesda, Maryland, 20892-1862, United

States.

Recebido em 26/08/07 Aceito em 06/09/07

\begin{abstract}
Primary pigmented nodular adrenocortical disease (PPNAD) is a form of bilateral adrenocortical hyperplasia that is often associated with corticotrophin (ACTH)-independent Cushing's syndrome (CS) and is characterized by small to normal-sized adrenal glands containing multiple small cortical pigmented nodules $(1,2)$. PPNAD may occur in an isolated form or associated with a multiple neoplasia syndrome, the complex of spotty skin pigmentation, myxomas, and endocrine overactivity, or Carney complex, in which Cushing's syndrome is the most common endocrine manifestation (3). Molecular studies have led to the identification of several genes, defects in which may predispose PPNAD formation; all of these molecules play important role for the CAMP signaling pathway. This review intends to present the most recent knowledge of the pathology and molecular genetics of the benign bilateral adrenocortical lesions, as well as to discuss the modern tools for diagnostics and treatment of this condition. (Arq Bras Endocrinol Metab 2007;51/8:1238-1244)
\end{abstract}

Keywords: PPNAD; Cushing's syndrome; Adrenocortical hyperplasia; Carney complex; PRKAR1A; PDE11A

\section{RESUMO}

\section{Doença Adrenocortical Nodular Pigmentada Primária e Síndrome de Cushing.}

A doença adrenocortical nodular pigmentada primária (PPNAD) é uma forma de hiperplasia adrenocortical bilateral que está freqüentemente associada com a síndrome de Cushing (SC) ACTH-independente, sendo caracterizada por glândulas adrenais de tamanho pequeno ou normal contendo múltiplos nódulos corticais pigmentados pequenos. PPNAD pode ocorrer de forma isolada ou associada com uma síndrome de neoplasia múltipla, o complexo de manchas pigmentadas na pele (lentigíneas), mixomas e hiperatividade endócrina, ou complexo de Carney, no qual a SC é a manifestação endócrina mais comum. Estudos moleculares levaram à identificação de vários genes que, quando mutados, podem predispor à formação da PPNAD; todas essas moléculas têm um papel importante na via de sinalização do AMPc. Esta revisão pretende apresentar os conhecimentos mais recentes sobre a patologia e a genética molecular das lesões adrenocorticais benignas bilaterais e discutir os modernos instrumentos para diagnóstico e tratamento dessa condição. (Arq Bras Endocrinol Metab 2007;51/8:1238-1244)

Descritores: PPNAD; Síndrome de Cushing; Hiperplasia adrenocortical; Complexo de Carney, PRKAR1A; PDE11A 
$\mathrm{H}$ ISTORICALLY, THE FIRST REPORTS of putative PPNAD can be traced back to 1978 when Acre et al. described four sibs with familial Cushing's syndrome (4). Histological analysis of the adrenals of three of them demonstrated enlarged glands containing numerous yellow cortical nodules ranging in size from 0.3 to $1.5 \mathrm{~cm}$ and containing lipochromic pigment (4). Three years later Donaldson et al. (5) described brother and sister with congenital Cushing's syndrome due to nodular bilateral adrenocortical hyperplasia (BACH). Subsequent investigations showed elevated urinary cortisol metabolites, 17-oxosteroids and 3 betahydroxy-5-ene-steroids; these were not suppressed by dexamethasone, and plasma ACTH was undetectable, indicating that the disorder was not due to excessive ACTH secretion (5). The term "primary pigmented nodular adrenocortical disease" was suggested to describe the disease in 1984 by Shenoy et al. (6), who reported four patients with Cushing's syndrome due to autonomously functioning bilateral adrenocortical neoplasms. After curative adrenalectomy, pathology findings included decreased, normal, or slightly increased total gland weight, multiple small (less than $4 \mathrm{~mm}$ ) black, brown, dark-green, red, or yellow nodules, and cortical atrophy and disorganization of the normal zonation between the nodules; lipofuscin was present within most of the enlarged cortical cells.

Nowadays PPNAD is mostly known as one of the manifestations of Carney complex (3). Although rarely, isolated PPNAD are also reported, and genetic studies indicate common molecular pathways involved in the pathology of PPNAD seen isolated or in the context of Carney complex. Herein we intend to summarize the current knowledge on PPNAD and its involvement in Carney complex, as well as to review the most recent findings on the molecular mechanisms underlying the disease.

\section{PPNAD AND ITS INVOLVEMENT IN CARNEY COMPLEX}

PPNAD is usually characterized by small to normalsized glands containing multiple black or brown nodules, most often surrounded by atrophic cortex (figure 1) (1). This atrophy is pathognomonic and reflects the autonomous function of these nodules and the suppressed levels of pituitary ACTH. Despite their small size (less than $6 \mathrm{~mm}$ ), the nodules are visible with computer tomography (CT-scan) or magnetic resonance imaging (MRI) of the adrenal glands, most likely because of the surrounding atrophy (7). The com- bination of atrophy and nodularity gives the glands an irregular contour, which is distinctly abnormal and diagnostic, especially in younger patients with CS. Patients with PPNAD often present with a variant CS called "atypical" (ACS) (8) which is characterized by an asthenic, rather than obese, body habitus. This phenotype is caused by severe osteoporosis, short stature, and severe muscle and skin wasting. Patients with ACS tend to have normal or near-normal 24-hour urinary free cortisol (UFC) production, but this is characterized by the absence of the normal circadian rhythmicity of cortisol $(9,10)$. Occasionally, normal cortisol production is interrupted by days or weeks of hypercortisolism, which gives rise to a yet another variant called "periodic CS" (PCS). PCS is frequently found in children and adolescents with PPNAD (10). In both ACS and PCS, as well as in classic CS, caused by PPNAD, paradoxical increase of UFC and/or 17hydroxy-corticosteroids (17-OHS) is seen during the second phase (high dose dexamethasone administration) of the Liddle's test (11). This feature may be useful diagnostically for PPNAD (11); it reflects, perhaps, a tendency that these nodules have for increased responsiveness to other steroids (12).

PPNAD may occur independently or, more commonly, as part of Carney complex, a multiple neoplasia syndrome described in $1985(1,13,14)$. CNC is associated with many other lesions, including cardiac myxomas and other cutaneous tumors, breast myxomatosis, spotty skin pigmentation and other lesions, pituitary adenomas and acromegaly, large-cell calcifying Sertoli cell tumors (among the rarest of testicular neoplasms), adrenocortical lesions, and Leydig cell tumors, psammomatous melanotic schwannoma, epithelioid blue nevus, and ductal adenoma of the breast and thyroid follicular neoplasms, both benign and malignant (15). With the report of CNC syndrome

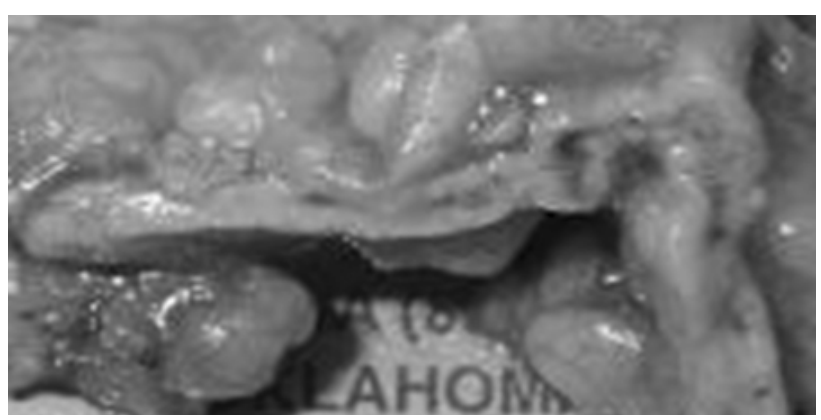

Figure 1. Primary pigmented nodular adrenocortical disease (PPNAD) with the characteristic relatively small adrenals and pigmented nodules. 
in 1985 it was realized that the majority of patients previously characterized under the separate diagnoses of LAMB (lentigines, atrial myxoma, mucocutaneous myxoma, blue nevi) and NAME (nevi, atrial myxoma, myxoid neurofibroma, ephelide), would now be more appropriately described under CNC $(16,17)$.

Most of the CNC cases are familiar; in the affected families the disease is inherited in an autosomal dominant manner (3). Previous estimations had indicated that approximately half of the cases are sporadic; recent diagnosis review and application of stringent screening criteria of all first-degree relatives of the affected patients led to re-estimation of the familiar cases to more than $70 \%(3)$.

More than $90 \%$ of the reported PPNAD cases are associated with $\mathrm{CNC}$ (18). Although known as its most frequent endocrine manifestation, PPNAD incidence among CNC patients depends on its presentation and might not reflect the true prevalence. In contrast to Cushing's syndrome medical records, indicating PPNAD presence in only between 25 and $45 \%$ of CNC patients, autopsy summaries report constant histological evidences for PPNAD associated with CNC. This discrepancy is likely due to the frequently atypical PPNAD manifestation - although it may cause "classic" Cushing's syndrome, PPNAD often presents with atypical, subclinical or cyclic hypercotisolism.

Although rare, familial cases of isolated PPNAD have also been reported (19). Like CNC, PPNAD is inherited in an autosomal dominant manner. Usually no other clinical features associated with CNC are seen in these families, however, it is worth to note that subtle disease manifestations could have been missed $(20,21)$.

PPNAD presents with bimodal age of distribution - although most of the cases are diagnosed in the second and third decade of life, a substantial proportion of patients present during their early childhood $(2-3$ yr) (3). Comprehensive PPNAD evaluation in the last several years suggested that the early onset bilateral adrenocortical hyperplasia $(\mathrm{BACH})$ may represent distinct disease entity, which, although very similar to PPNAD, displays some specific features in the mode of pigmentation and the nodules distribution $(22,23)$.

\section{MOLECULAR GENETICS}

Initially, two genetic loci have been identified for $\mathrm{CNC}-$ one on chromosome $2 \mathrm{pl} 6(24,25)$ and one on chromosome 17q22-23 (26). The gene responsible for $\mathrm{CNC}$ at the chromosome $2 \mathrm{pl} 6$ region is yet to be revealed. Comprehensive analysis of the $17 \mathrm{q} 22-23$ region identified inactivating germline mutations in CNC patients in the gene coding for PRKARIA one of the regulatory subunits of PKA (26); to date, more than $60 \%$ of CNC patients are identified to harbor pathogenic PRKARIA mutations.

PRKARIA is one of the several types of regulatory subunits that comprise one of the two homodimers that form the PKA holoenzyme - the main mediator of cAMP signaling in mammals; the other homodimer is composed of two catalytic molecule subunits (26-29). Elevation in the cellular cAMP levels, and, consequently, binding of cAMP molecules to the regulatory subunits leads to activation of the regulatory subunits, dissolution of the holoenzyme and release of the catalytic subunits. Thus, functionally, inactivation of PRKARIA is associated with excess PKA signaling in affected tissues (30).

Several cAMP-PKA pathways are operational at any given moment in the cell. Activated PKA can phosphorylate different targets in response to different stimuli. Signal specificity is mediated by tissue specific expression of the regulatory and catalytic subunits, compartmentalization of the tetramer by A-kinase anchoring proteins (AKAPs) and other factors (3133). Through compartmentalization of the PKA holoenzymes the cAMP messaging is targeted to specific subcellular locations, such as the cytoskeleton, plasma membrane, nucleus, Golgi apparatus, endoplasmic reticulum and other organelles.

PRKARIA is comprised of 11 exons, with total genomic extent approximately $21 \mathrm{~kb}$, and coding region of $1,143 \mathrm{bp}$, starting from exon 2 . Since the identification of PRKARIA mutations in Carney complex, a large number of sequencing defects have been found. The vast majority of the mutations consist of base substitutions, small deletions and insertions or combined rearrangements, involving up to 15 bp (26, 27); although rare, large PRKARIA deletions have been recently identified (Horvath et al., unpublished data). In more than $90 \%$ of the mutations, the sequence change results in a premature stop codon; this leads to degradation of mutant mRNAs by nonsense mediated mRNA decay and, consequentially, the absence of the predicted mutant protein product (27). Loss of the normal 17q22-23 allele in CNC lesions (loss-of-heterozygosity, LOH) has also been noted, implicating PRKARIA as a classic tumor-suppressor gene (34). The observation in these studies that neither the normal PRKARIA protein nor the mutant allele was present in tumors from $\mathrm{CNC}$ patients suggested that the oncogenesis in CNC tumors was due to the complete lack of a functional PRKARlA (35). 
Although rarely, mutations that escape NMD and lead to the expression of an abnormal, defective PRKARIA protein have been identified (19, Horvath et al. [unpublished data], Greene et al. [unpublished data]). Notably, the expressed mutations can lead to specific phenotype manifestations that reflect the type and the severity of the molecular PRKARIA defect. For instance, a splice-site variant that eliminates "in frame" exon 7 is seen associated mostly with isolated PPNAD, presumably due to adrenal-specific expression regulation, possibly partial splicing effect of the variant (not $100 \%$ of the molecules harboring the mutation are subjected to defective splicing) and sensitivity of the adrenal gland to even subtle alterations in the cAMP signaling (19). In contrast, germline "in frame" deletion of exon 3 results in severe expression of the majority of the CNC manifestations - this phenotype likely reflects the importance of exon 3 , linking the dimerisation/docking domain and the first cAMP binding domain for the overall functional conformation of PRKARIA. Genotype-phenotype correlation is absent in premature stop-codon generating mutations - as NMD smoothen the distinct potential of the various changes to express effect on the cellular processes, the major outgrow of these mutations is PRKARIA haploinsufficiency.

In search for genetic locus for early onset bilateral adrenocortical, a genome wide screen of 10 kindreds negative for PRKARIA mutations identified strong association with inactivating mutations in phosphodiesterase 11A (PDE11A), located on chromosome $2 \mathrm{q} 31.2(23,36)$. Some of the patients included in this study displayed PPNAD features different from the classical manifestations. Most of the affected individuals had an overall normal adrenal glands size and weight that featured multiple small yellow-to-dark brown nodules surrounded by a cortex with a uniform appearance. Microscopy showed moderate diffuse cortical hyperplasia with multiple capsular deficits and massive circumscribed and infiltrating extra-adrenal cortical excrescences with micronodules. Although the regular microscopy revealed mostly nonpigmented nodules, the electron microscopy uncovered granules of lipofuscin and features of a cortisol-producing adrenocortical hyperplasia. In the remaining individuals the PPNAD manifestations were not distinguishable from those caused by PRKARIA mutations (2).

PDE11A belongs to the huge family of human phosphodiesterases (PDE) comprised by 21 so far identified genes that are classified in 11 different families based on structural similarity such as sequence homology, protein domains, and enzymatic properties including substrate specificity, kinetic properties, and sensitivity to endogenous regulators and inhibitors (reviewed in 39). PDEllA catalyzes the hydrolysis of both cAMP and cyclic GMP (cGMP) and is expressed in several endocrine tissues, including the adrenal cortex $(37,38)$. It is composed from 2 GAF and a catalytic domain; two $\mathrm{N}$-terminal phosphorilation sites for PKA and PKG are identified (39). The gene spans approximately $0.5 \mathrm{MB}$ and is composed by 23 exons which alternative splicing results in the expression of four different isoforms PDE11A1, PDE1IA2, PDEIIA3, and PDEIIA4 (39). Of the four, only the full length (PDE11A4, $2.8 \mathrm{~KB}$ ) shows high adrenal specific expression.

Five different PDE1IA mutations were identified so far among the patients with isolated PPNAD 3 of them resulted in premature stop codon generation; the remaining 2 were single-base substitutions in the catalytic domain of the protein and were shown to significantly affect the ability of PDEllA to degrade cAMP in vitro (36). Notably, all the five sequence variants were seen in general population, although with significantly lower frequency (36). The incomplete penetrance of functionally harmful PDEIIA sequence variation needs further investigation - it may reflect the complementing mode of action of the phosphodiesterases in the cAMP cellular levels regulation; alternatively, other genetic variants that act concertedly with the PDEllA mutations may take place. The number of factors likely to affect tumorigenicity by these mutations may be the reason for their apparent low penetrance; as in the adrenal cortex, these factors are likely to be developmental, hormonal, and gender related. For example, adrenocortical tumors and Cushing syndrome are generally more frequent in females, and almost all of the probands studied here or in our previous investigations $(23,36)$ were females. On the other hand, in all cases where inheritance of the PDE1IA mutation could be proved, the asymptomatic carrier was the father $(23,36)$. In addition, the presence of allelic losses of the corresponding normal allele in adrenal tissues seems to be a determining factor in the development of an adrenal tumor as it is suggested by the PDEIIA-associated tumor genetic studies (36).

Another type of bilateral adrenocortical hyperplasia leading to Cushing syndrome - macronodular adrenocortical hyperplasia - is associated with somatic mutations in the gene coding for GNAS complex locus (GNAS) in McCune-Albright syndrome (MAS) (40). The frequency with which carriers of mutations in PRKARIA and PDEIIA present with classic Cushing syndrome seems to be higher than in disease asso- 
ciated with GNAS, whereas the age at which Cushing syndrome presents in these disorders is exactly the reverse: GNAS mutation carriers present with Cushing syndrome almost always in infancy, whereas PDE11A or PRKARIA mutation carriers present with Cushing syndrome in childhood and young adulthood.

\section{CLINICAL EVALUATION AND GENETIC TESTING}

PPNAD often presents in an indolent fashion and may be difficult to diagnose due to an intermittent or cyclical nature of the associated hypercortisolism. In addition to UFC we recommend diurnal cortisol levels (11.30 pm, $12.00 \mathrm{MN}$ and $7.30 \mathrm{am}, 8.00 \mathrm{am}$ sampling) and/or dexamethasone-stimulation test (modified Liddle's test), and adrenal computed tomography $(3,41)$. Molecular testing for PRKARIA and PDEIIA mutations may be advised for detection of affected patients in families with known mutations of that gene to avoid unnecessary medical surveillance of non-carriers.

PPNAD is a non-malignant lesion; however, surgery is indicated because the mortality among patients with PPNAD is the same as those associated with Cushing's syndrome (CS) $(3,42)$. Patients with PPNAD should be followed by screening for CNC and its potentially fatal components $(1,43)$.
Diagnostic criteria for $\mathrm{CNC}$ have been reviewed recently and are listed in table 1 (6, Sandrini). To make a diagnosis of Carney complex, a patient must either: (i) exhibit two of the manifestations of the disease listed below, or (ii) exhibit one of these manifestations and meet one of the supplemental criteria (an affected first-degree relative or an inactivating mutation of the PRKARlA gene).

The recommended clinical surveillance of patients with CNC differs per age group. For postpubertal pediatric and adult patients we recommend annual echocardiogram (this study may be needed biannually for adolescent patients with a history of excised myxoma), testicular and thyroid ultrasound, and UFC and serum IGF-1 levels. For pre-pubertal pediatric patients, we recommend annual echocardiogram (biannually for patients with a history of excised myxoma) and testicular ultrasound for boys. If close monitoring of growth rate and pubertal staging indicates other abnormalities, such as possible Cushing syndrome appropriate testing should be done as needed.

\section{CONCLUDING REMARKS}

Over the last years the molecular studies revealed important cellular mechanisms that underlie adrenocortical tumor formation and progression; they also

Table 1. Diagnostic criteria for Carney complex.

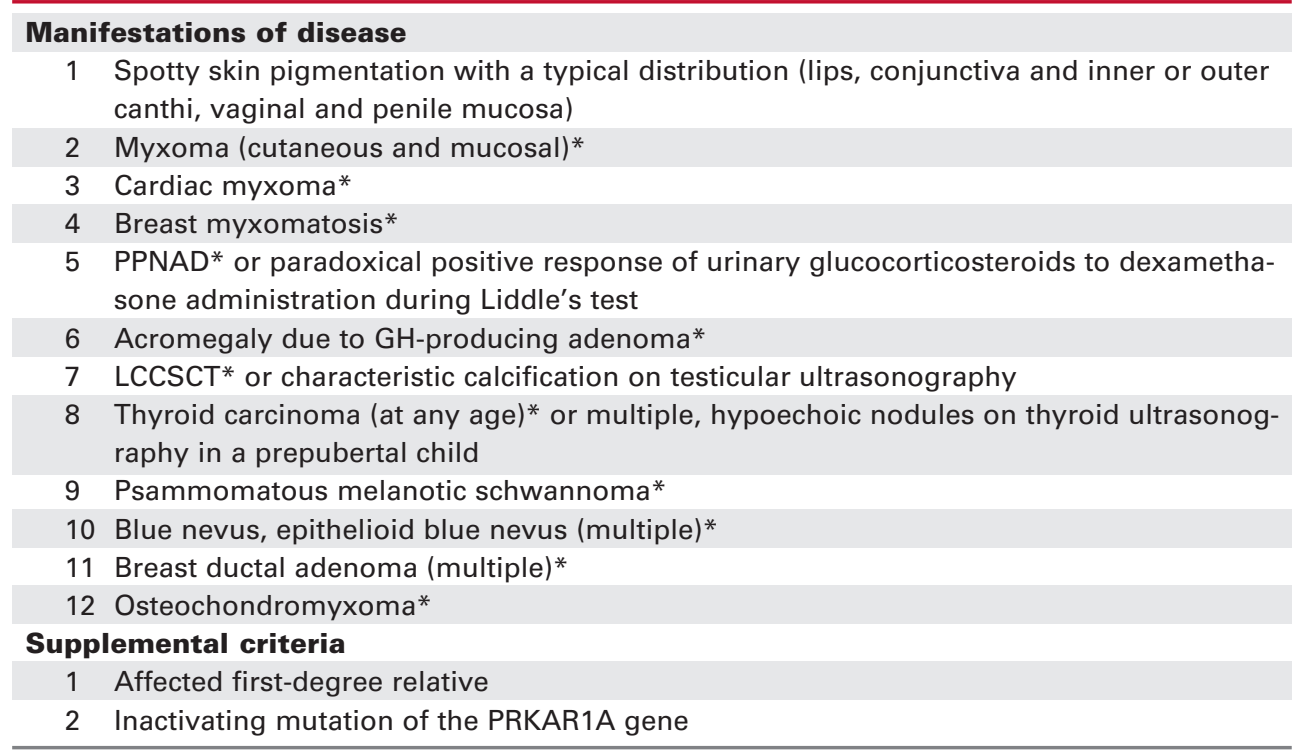

* With histological confirmation 


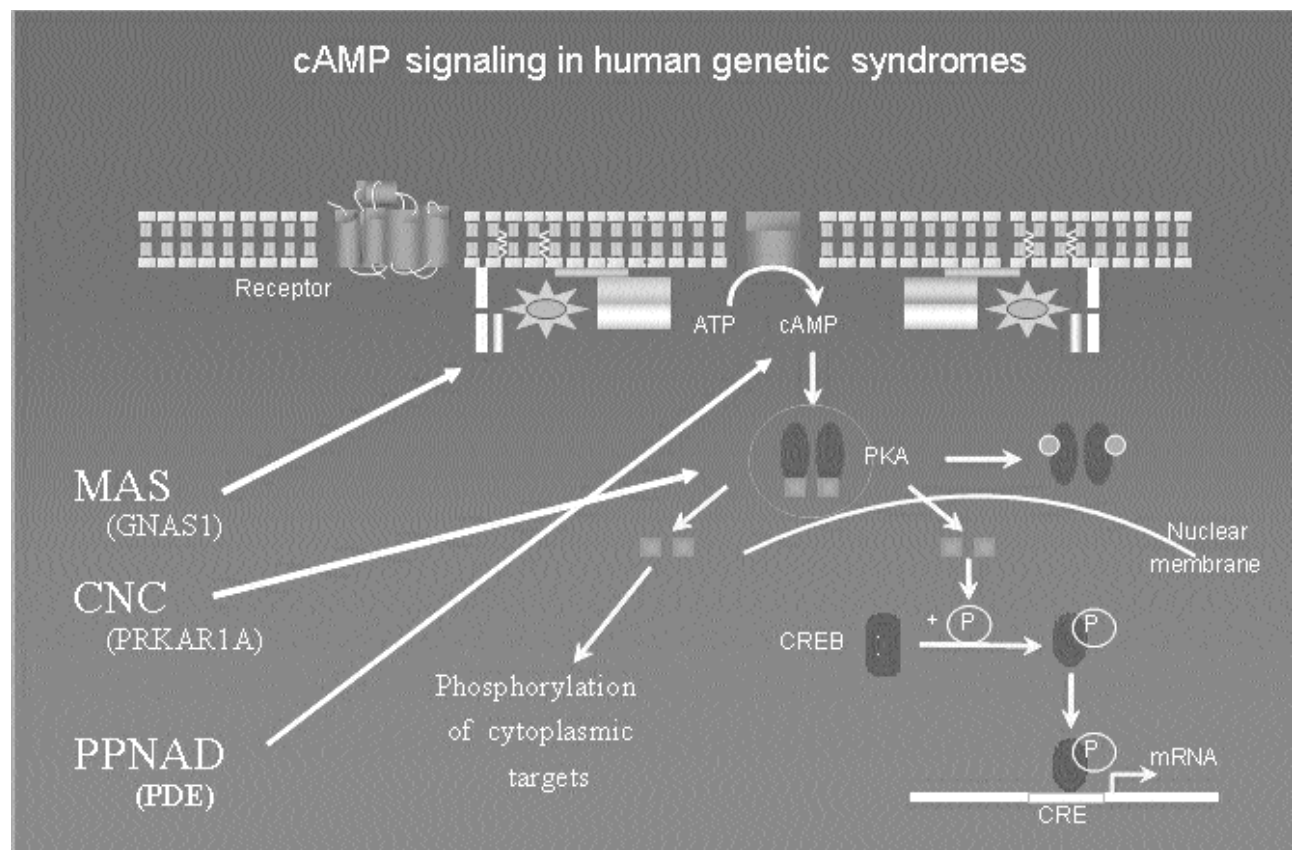

Figure 2. cAMP signaling in human genetic diseases.

suggested useful diagnostic and therapeutic tools for better disease management. The genetic defects identified in PRKARIA, PDEIIA and GNASI, all of them key components of the cAMP signaling pathway, demonstrate the importance of the cAMP regulation for the proper functioning of the adrenocortical cell and signify the need for its further exploration in adrenocortical lesions (figure 2). The incomplete penetrance of PDE1IA mutations is suggestive for a complementing action of the different PDEs in the adrenal gland, and the possible involvement of other members of this gene family in the adrenocortical signaling regulation. The very rarely observed incomplete penetrance of PRKARIA mutations, associated mostly with adrenal phenotype indicates that the adrenal cortex is the first tissue to respond to even subtle alterations in the cAMP levels.

\section{REFERENCES}

1. Carney JA, Young WF. Primary pigmented nodular adrenocortical disease and its associated conditions. Endocrinologist 1992:2:6-21.

2. Stratakis CA, Kirschner LS. Clinical and genetic analysis of primary bilateral adrenal diseases (micro- and macronodular disease) leading to Cushing syndrome. Horm Metab Res 1998;30:456-63.

3. Stratakis CA, Kirschner LS, Carney JA. Clinical and molecular features of the Carney complex: diagnostic criteria and recommendations for patient evaluation. J Clin Endocrinol
Metab 2001;86:4041-6.

4. Arce B, Licea M, Hung S, Padron R. Familial Cushing's syndrome. Acta Endocrinol (Copenh) 1978;87(1):139-47.

5. Donaldson MD, Grant DB, O'Hare MJ, Shackleton CH. Familial congenital Cushing's syndrome due to bilateral nodular adrenal hyperplasia. Clin Endocrinol (Oxf) 1981;14:519-26.

6. Shenoy BV, Carpenter PC, Carney JA. Bilateral primary pigmented nodular adrenocortical disease. Rare cause of the Cushing syndrome. Am J Surg Pathol 1984;8:335-44.

7. Doppman JL, Travis WD, Nieman L, Miller DL, Chrousos GP, Gomez MT, et al. Cushing syndrome due to primary pigmented nodular adrenocortical disease: findings at CT and MR imaging. Radiology 1989;172:415-20.

8. Mellinger RC, Smith RW Jr. Studies of the adrenal hyperfunction in 2 patients with atypical Cushing's syndrome. J Clin Endocrinol Metab 1956;16:350-66.

9. Sarlis NJ, Chrousos GP, Doppman JL, Carney JA, Stratakis CA. Primary pigmented nodular adrenocortical disease: reevaluation of a patient with Carney complex 27 years after unilateral adrenalectomy. J Clin Endocrinol Metab 1997;82:1274-8.

10. Gomez Muguruza MT, Chrousos GP. Periodic Cushing syndrome in a short boy: usefulness of the ovine corticotropin releasing hormone test. J Pediatr 1989;115:270-3.

11. Sarlis NJ, Papanicolaou DA, Chrousos GP, Stratakis CA. Paradoxical increase of urinary free cortisol and 17-hydroxysteroids to dexamethasone during Liddle's test: a diagnostic test for primary pigmented adrenocortical disease. [Abstract P2 - 76]. In: Proceedings of the 79th Annual Meeting of the Endocrine Society in Minneapolis, MN, Endocrine Society Press, 1997. p. 303.

12. Caticha O, Odell WD, Wilson DE, Dowdell LA, Noth RH, Swislocki $A L$, et al. Estradiol stimulates cortisol production by adrenal cells in estrogen-dependent primary adrenocortical nodular dysplasia. J Clin Endocrinol Metab 1993;77:494-7.

13. Carney JA, Gordon H, Carpenter PC, Shenoy BV, Go VL. The complex of myxomas, spotty pigmentation, and endocrine overactivity. Medicine (Baltimore) 1985;64:270-83.

14. Carney JA, Hruska LS, Beauchamp GD, Gordon H. Dominant 
inheritance of the complex of myxomas, spotty pigmentation, and endocrine overactivity. Mayo Clin Proc 1986;61:165-72.

15. Stratakis CA, Courcoutsakis NA, Abati A, Filie A, Doppman $\mathrm{JL}$, Carney JA, et al. Thyroid gland abnormalities in patients with the syndrome of spotty skin pigmentation, myxomas, endocrine overactivity, and schwannomas (Carney complex). J Clin Endocrinol Metab 1997;82:2037-43.

16. Rhodes AR, Silverman RA, Harrist TJ, Perez-Atayde AR. Mucocutaneous lentigines, cardiomucocutaneous myxomas, and multiple blue nevi: the "LAMB" syndrome. J Am Acad Dermatol 1984;10:72-82.

17. Atherton DJ, Pitcher DW, Wells RS, MacDonald DM. A syndrome of various cutaneous pigmented lesions, myxoid neurofibromata and atrial myxoma: the NAME syndrome. $\mathbf{B r} \mathbf{J}$ Dermatol 1980;103:421-9.

18. Kirschner LS, Taymans SE, Stratakis CA. Characterization of the adrenal gland pathology of Carney complex, and molecular genetics of the disease. Endocr Res 1998;24:863-4.

19. Groussin L, Horvath A, Jullian E, Boikos S, Rene-Corail F, Lefebvre $\mathrm{H}$, et al. A PRKAR1A mutation associated with primary pigmented nodular adrenocortical disease in 12 kindreds. J Clin Endocrinol Metab 2006:91:1943-9.

20. Armstrong DK, Irvine AD, Handley JM, Walsh MY, Hadden DR, Bingham EA. Carney complex: report of a kindred with predominantly cutaneous manifestations. $\mathbf{B r} \mathbf{J}$ Dermatol 1997;136:578-82.

21. Liebler GA, Magovern GJ, Park SB, Cushing WJ, Begg FR, Joyner CR. Familial myxomas in four siblings. J Thorac Cardiovasc Surg 1976;71:605-8.

22. Gunther DF, Bourdeau I, Matyakhina L, Cassarino D, Kleiner $\mathrm{DE}$, Griffin K, et al. Cyclical Cushing syndrome presenting in infancy: an early form of primary pigmented nodular adrenocortical disease, or a new entity? J Clin Endocrinol Metab 2004;89:3173-82.

23. Horvath A, Boikos S, Giatzakis C, Robinson-White A, Groussin $L$, Griffin KJ, et al. A genome-wide scan identifies mutations in the gene encoding phosphodiesterase 11A4 (PDE11A) in individuals with adrenocortical hyperplasia. Nat Genet 2006;38:794-800.

24. Stratakis CA, Jenkins RB, Pras E, Mitsiadis CS, Raff SB, Stalboerger PG, et al. Cytogenetic and microsatellite alterations in tumors from patients with the syndrome of myxomas, spotty skin pigmentation, and endocrine overactivity (Carney complex). J Clin Endocrinol Metab 1996;81:3607-14.

25. Taymans SE, Kirschner LS, Giatzakis C, Stratakis CA. Radiation hybrid mapping of chromosomal region 2p15-p16: integration of expressed and polymorphic sequences maps at the Carney complex (CNC) and Doyne honeycomb retinal dystrophy (DHRD) loci. Genomics 1999;56:344-9.

26. Kirschner LS, Carney JA, Pack SD, Taymans SE, Giatzakis C, Cho YS, et al. Mutations of the gene encoding the protein kinase $\mathrm{A}$ type I-alpha regulatory subunit in patients with the Carney complex. Nat Genet 2000;26:89-92.

27. Kirschner LS, Sandrini F, Monbo J, Lin JP, Carney JA, Stratakis CA. Genetic heterogeneity and spectrum of mutations of the PRKAR1A gene in patients with the Carney complex. Hum Mol Genet 2000;9:3037-46.

28. Bossis I, Stratakis CA. Minireview: PRKAR1A: normal and abnormal functions. Endocrinology 2004;145:5452-8.

29. Groussin L, Jullian E, Perlemoine K, Louvel A, Leheup B, Luton JP, et al. Mutations of the PRKAR1A gene in Cushing's syndrome due to sporadic primary pigmented nodular adrenocortical disease. J Clin Endocrinol Metab 2002;87:4324-9.

30. Robinson-White A, Meoli E, Stergiopoulos S, Horvath A,
Boikos S, Bossis I et al. PRKAR1A mutations and protein kinase $A$ interactions with other signaling pathways in the adrenal cortex. J Clin Endocrinol Metab 2006;91:2380-8.

31. Colledge M, Scott JD. AKAPs: from structure to function. Trends Cell Biol 1999;9:216-21.

32. Wang L, Sunahara RK, Krumins A, Perkins G, Crochiere ML, Mackey $M$, et al. Cloning and mitochondrial localization of full-length D-AKAP2, a protein kinase A anchoring protein. Proc Natl Acad Sci U S A 2001;98:3220-5.

33. Griffioen G, Thevelein JM. Molecular mechanisms controlling the localisation of protein kinase A. Curr Genet 2002:41:199-207.

34. Stratakis CA. Mutations of the gene encoding the protein kinase A type l-alpha regulatory subunit (PRKAR1A) in patients with the "complex of spotty skin pigmentation, myxomas, endocrine overactivity, and schwannomas" (Carney complex). Ann N Y Acad Sci 2002;968:3-21.

35. Groussin L, Kirschner LS, Vincent-Dejean C, Perlemoine K, Jullian E, Delemer B, et al. Molecular analysis of the cyclic AMP-dependent protein kinase $A(P K A)$ regulatory subunit $1 \mathrm{~A}$ (PRKAR1A) gene in patients with Carney complex and primary pigmented nodular adrenocortical disease (PPNAD) reveals novel mutations and clues for pathophysiology: augmented PKA signaling is associated with adrenal tumorigenesis in PPNAD. Am J Hum Genet 2002;71:1433-42.

36. Horvath A, Giatzakis C, Robinson-White A, Boikos S, Levine E, Griffin K, et al. Adrenal hyperplasia and adenomas are associated with inhibition of phosphodiesterase $11 \mathrm{~A}$ in carriers of $P D E 11 A$ sequence variants that are frequent in the population. Cancer Res 2006;66:11571-5.

37. Loughney K, Taylor J, Florio VA. 3',5'-cyclic nucleotide phosphodiesterase 11A: localization in human tissues. Int $\mathbf{J}$ Impot Res 2005;17:320-5.

38. D'Andrea MR, Qiu Y, Haynes-Johnson D, Bhattacharjee S, Kraft P, Lundeen S. Expression of PDE11A in normal and malignant human tissues. J Histochem Cytochem 2005;53:895-903.

39. Omori K, Kotera J. Overview of PDEs and their regulation. Circ Res 2007:100:309-27.

40. Bourdeau I, Stratakis CA. Cyclic AMP-dependent signaling aberrations in macronodular adrenal disease. Ann $\mathbf{N} \mathbf{Y}$ Acad Sci 2002;968:240-55.

41. Bourdeau I, Lacroix A, Schurch W, Caron P, Antakly T, Stratakis CA. Primary pigmented nodular adrenocortical disease: Paradoxical responses of cortisol secretion to dexamethasone occur in vitr and are associated with increased expression of the glucocorticoid receptor. J Clin Endocrinol Metab 2003;88:3931-7.

42. Stratakis CA, Carney JA, Lin JP, Papanicolaou DA, Karl M, Kastner DL, et al. Carney complex, a familial multiple neoplasia and lentiginosis syndrome. Analysis of 11 kindreds and linkage to the short arm of chromosome 2. J Clin Invest 1996;97:699-705.

Address for correspondence:

Constantine A. Stratakis

Head, Section on Endocrinology \& Genetics (SEGEN)

DEB, NICHD, National Institutes of Health

10 Center Drive, Building 10/CRC, Room 1E-3330, MSC 1103 Bethesda, MD 20892

Fax: 301-402-0574

E-mail: stratakc@mail.nih.gov 